\title{
Evaluation of medical student retention of clinical skills following simulation training
}

Gozie Offiah, Lenin P. Ekpotu, Siobhan Murphy, Daniel Kane, Alison Gordon, Muireann O'Sullivan, Sue Faye Sharifuddin, A. D. K. Hill and Claire M. Condron ${ }^{*}$ (i)

\begin{abstract}
Background: Adequate clinical skills training is a challenge for present day medical education. Simulation Based Education (SBE) is playing an increasingly important role in healthcare education worldwide to teach invasive procedures. The impact of this teaching on students along with retention of what is taught is not fully understood. The purpose of this study was to evaluate the retention levels of practical skills taught and assessed by SBE and to explore the degree of re-training required to restore decayed performance. In exploring this aim, the study further investigates how skilled performance decays over time and which dimensions of clinical skills were more likely to decay.

Methods: Study participants were 51 final year medical students. They were provided with online pre-course videos and procedural guides asynchronously with repeatedly access. 7 of the skills taught over 2 years using task trainers were selected. Following demonstration from faculty, students practiced in small groups with faculty facilitated supervision and peer support prior to formal testing. Score sheets with itemised procedure checklists detailing the minimum passing standard (MPS) for each skill were designed. To test retention of skills, 18 months later, there was an unannounced test to demonstrate proficiency in the skills. Students were asked to complete a questionnaire indicating how many times and where they had practiced or performed the skills.
\end{abstract}

Results: $55 \%$ of the students were deficient in 3 or more skills and $4 \%$ were not competent in 5 or more skills. A significant number of students had never practiced some skills following the initial teaching session. A relationship was noted with the number of times students self-declared that they had practiced and their performance. Decay is evident in both psychomotor and cognitive domains of the skills.

Conclusion: A curriculum with deliberate practice significantly increases the competence of students in defined clinical skills. Deliberate practice of clinical skills, under supervision of an engaged instructor, is a key component of the mastery model. Experiences and assessments in the clinical setting need to be augmented with focus on direct observation and focused feedback to reinforce the skills acquired in the simulated setting.

Keywords: Simulation, Retention, Clinical skills, Medical school curriculum, Psychomotor and cognitive domains, Deliberate practice

\footnotetext{
* Correspondence: ccondron@rcsi.ie

Department of Surgery, Royal College of Surgeons in Ireland Education and

Research Centre, Beaumont Hospital, Dublin 9, Ireland
}

(c) The Author(s). 2019 Open Access This article is distributed under the terms of the Creative Commons Attribution 4.0 International License (http://creativecommons.org/licenses/by/4.0/), which permits unrestricted use, distribution, and reproduction in any medium, provided you give appropriate credit to the original author(s) and the source, provide a link to the Creative Commons license, and indicate if changes were made. The Creative Commons Public Domain Dedication waiver (http://creativecommons.org/publicdomain/zero/1.0/) applies to the data made available in this article, unless otherwise stated. 


\section{Background}

Clinical skills are a key domain of good professional practice and recently there has been a greater recognition of the performance-based component of clinical competency [1]. Inadequate clinical skills training is a significant problem of present-day medical education [2]. Many procedures are potentially dangerous due to their invasive nature and thus difficult to teach and learn. Simulation based education (SBE) is playing an increasingly important role in healthcare education worldwide. In addition to reducing risk to patients, simulation is valued for the ability to create conditions that optimise learning. Intricate elements of a difficult procedure can be selectively rehearsed again and again, and learners reach competence through deliberate and repeated practice aided by timely feedback and appropriate reflection.

Engaging in deliberate practice with use of simulation, reflection and feedback develops expertise and this has been well documented in the literature [3]. Clinical competence is defined as having "the knowledge and skills for safe and effective practice when working without direct supervision" [4]. Clinical skill mastery is developmental, thus clinical skills education must be an integrated and longitudinal educational process. Several studies have shown that the use of low fidelity simulator improves both the technical performance but also the ability to attend to the cognitive components of the skill [5]. Cognitive skills training enhances the ability to correctly execute a technical skill and thus needs specific focus within the medical school curriculum [6].

\section{Objectives}

The aim of our study was to investigate clinical skills performance over a period following SBE training in an undergraduate medical curriculum. We hypothesized that certain dimensions of clinical skills performance are more subject to decay over time. Does the cognitive learning or the technical skill learning decay more? Identifying the aspects that decay more than others will lead to designing interventions to strengthen any component skills.

\section{Methods}

\section{Study design}

Medical students' skills decay was investigated in observational prospective cohort study.

\section{Setting}

The study was carried out with final year medical students at the Royal College of Surgeons in Ireland (RCSI). Ethical approval for the study was obtained from the RCSI ethics committee (number REC 1362).
Skills training is focussed in the third, fourth and final years. A mastery learning approach was taken to teach 7 practical skills over the 2 years between third year and final fifth year to undergraduate medical students. Learning resources incorporating procedural guides and videos were provided on-line prior to the initial training and available for students to repeatedly use at any time. A faculty led programme provided skill demonstration using task trainers and facilitated mentored practice. Students practiced with faculty supervision and peer support before undergoing formal testing using a scoresheet detailing the minimum passing standard (MPS). The MPS was set by consensus from a group of educators across the different specialities and departments within the institution teaching these skills.

The initial training course provided the necessary educational experiences for repetitive practice required to reach competency and remediation when necessary.

\section{Participants and study size}

In their final medical year, 51 students attended and consented to an unannounced test to demonstrate skills proficiency which was held between 12 and 24 months of their initial training sessions. This groups consisted of $48 \%$ females and $52 \%$ males. This was a convenience sample which was representative of the class as a whole.

\section{Bias}

Selection bias maybe considered a limitation of this study in that students volunteered for the noncompulsory retesting. Voluntary participation was a condition of our study ethics permission and this was achieved by adding the retesting stations onto an induction session for the student's sub-internship which is the final student clerkship in our institution. Some students were taken aback at the idea of unannounced testing and were initially reluctant to participate in retesting. However as they witnessed others classmates participating, in the retesting and associated retraining they immediately saw the value in this opportunity and all but 2 consented to the resting of their skills.

\section{Data variables}

Table 1 shows the list of skills that were tested and the time period between initial teaching and re-test. Although all of the students received the initial teaching and assessment of the different skills in (with in) the same term and the retesting took place within (in) one term controlling for the retention time was not possible in this convenience sample and is a limitation of this study.

The MPS tool for each skill scored performance as done well, done adequately or done poorly/not done. 
Table 1 The skills that were tested and the time interval between teaching and re-test

\begin{tabular}{|c|c|c|c|}
\hline Clinical Skill & Skill initially taught & Year taught & Year Re-assessed (time interval) \\
\hline Venepuncture & 3rd medical year & $(2014 / 15)$ & 2017 (24 months) \\
\hline Cannulation & 4th medical year & $(2015 / 16)$ & 2017 (12 months) \\
\hline Male Catheterisation & 3rd medical year & $(2014 / 15)$ & 2017 (24 months) \\
\hline Blood Pressure & 3th medical year & $(2014 / 15)$ & 2017 (24 months) \\
\hline Sterile Field & 4th medical year & $(2015 / 16)$ & 2017 (12 months) \\
\hline Arterial Blood Gas & 4th medical year & $(2015 / 16)$ & 2017 (12 months) \\
\hline Blood Glucose & 4th medical year & $(2015 / 16)$ & 2017 (12 months) \\
\hline
\end{tabular}

Students were taught clinical skills throughout their 3rd and 4th year of medical school. Students volunteered to rest their competency at these skills during their final year just before their final clerkship

Students completed a questionnaire to report when and how many times they practiced their skills following initial teaching.

\section{Analysis}

To aid data analysis the individual elements of the minimum passing standard (MPS) for each skill were grouped into affective, psychomotor and cognitive type skills [7]. Table 2 shows the component parts of the score sheet aligned to Bloom's Taxonomy.

\section{Results}

Undergraduate medical students presented for unannounced practical skills testing using task trainer simulation immediately before their final clerkship $(n=$ 51 students). $45 \%$ of student retained the MPS in all 7 skills over the 2 -year period. $55 \%$ did not achieve the MPS in 3 or more skills and $4 \%$ did not achieve the MPS in 5 or more skills.

Of the 7 skills, male catheterisation was the most poorly retained skill while students performed best at venepuncture. The results demonstrate a correlation between the numbers of times that students self-declared that they had practiced the skills and a high competency rate as depicted in Table 3.

Further analysis of performance of 2 of the skills with the longest interval between initial teaching and assessment and the retesting was carried out. Venepuncture which students practiced repeatedly in the intervening

Table 2 MPS Score Sheets aligned to Bloom's Taxonomy

\begin{tabular}{ll}
\hline Affective/behavioural & Initial introduction \\
& Patient relationship building/ \\
& Communication skills \\
& Explanation and consent \\
Psychomotor & Individual MPS components of task \\
& Technique specific \\
Cognitive & Knowledge specific \\
& Stepwise completion of task
\end{tabular}

The Individual Component tasks of the MPS score sheets were grouped and aligned to Bloom's Taxonomy time and catheterisation which was practiced least by students. To facilitate this analysis the MPS were further categorised to affective, cognitive or psychomotor domains. Our result shows that different procedural skills have elements of decay from the different aspects of the blooms taxonomy domains of affective, cognitive and psychomotor when retested thus supporting the argument that deliberate repeated practice should include all components of the skills rather than just the technical aspects. It was noted that when students failed to reach the MPS at retesting the psychomotor aspects of these skills were performed poorly for both procedures. Interestingly, the behavioural aspect varied for both procedures. Students retained the behavioural aspects of the Venepuncture technique better compared to catheterisation as shown in Fig. 1.

Students understood the need to retest for competency and agreed that the correct time to address skills retention was before their final clerkship in our program. They felt more confident after the retest and prior to commencing their clerkship as depicted in Fig. 2. Students agreed that SBE provided a safe environment to practice skills.

Additionally, we evaluated where in the medical school curriculum these skills should be taught and the relevance for preparing medical students for clinical practice. 91 participants were asked to complete a Likert scale questionnaire. Table 4 below. Both interns (first year post graduation) and medical educators identified that these skills were required for safe intern practice yet $55 \%$ of our final year students did not reach competency at for 3 or more skills.

\section{Discussion}

Research shows that healthcare providers' skill retention declines as soon as three months after training $[8,9]$. Factors known to affect skills and knowledge acquisition include motivation, the learning environment [10] and the use of simulation to enhance skills retention for lowfrequency procedures [11]. Simulation-based mastery learning can improve medical students' retention of core 
Table 3 Students Self-declared Intensity of Practise for Each Skill

\begin{tabular}{llllll}
\hline Clinical Skill & $\begin{array}{l}\text { Spearman's rho } \\
\text { Correlation } \\
\text { coefficient }\end{array}$ & Never & Once & $\begin{array}{l}\text { More } \\
\text { than 5 }\end{array}$ & $\begin{array}{l}10 \text { or } \\
\text { more }\end{array}$ \\
\hline Aseptic Technique & 0.16 & 24 & 16 & 3 & 1 \\
Venepuncture & 0.73 & 4 & 9 & 25 & 9 \\
Blood Pressure & 0.72 & 2 & 3 & 25 & 16 \\
Arterial Blood Gas & 0.83 & 27 & 18 & 0 & 2 \\
Male Catheterisation & 0.11 & 30 & 13 & 2 & 1 \\
Cannulation & 0.34 & 12 & 18 & 12 & 5 \\
Blood Glucose & 0.09 & 14 & 15 & 13 & 5 \\
Monitoring & & & & & \\
\hline
\end{tabular}

Students filled in a questionnaire to detail how often they had practiced their skills. ( $n=51$ students). This self-report practice was correlated with the students' performance on retest of the individual skills

(Spearman's Correlation)

clinical skills and deliberate practice of clinical skills under the supervision of an engaged instructor is a key component of the mastery model [12]. Low-dose highfrequency training is a competence-building approach for training which uses targeted simulation-based learning activities that are spaced over time and reinforced with structured, ongoing practice sessions promoting maximum retention of clinical skills. Our study indicates that SBE can facilitate teaching clinical skills. The key question is how low-dose high-frequency simulation can be operationalized within the constraints of large undergraduate programs to help to reduce skills decay?

It is important to define the appropriate level of performance at stages of the curriculum and establish criterion levels for different levels of proficiency from novice to mastery. The MPS for clinical skills should be designed to ensure that the affective, psychomotor and cognitive elements of each skills are captured and to ensure as much uniformity as possible in the approach to generic elements. An entrustable professional activity (EPA) is "a core unit of professional practice that can be fully entrusted to a trainee, as soon as he or she has demonstrated the necessary competence to execute the activity unsupervised" [13]. It is hypothesised the introduction of EPAs into our curriculum with emphasis on longitudinal spiral skills mastery, with increasing
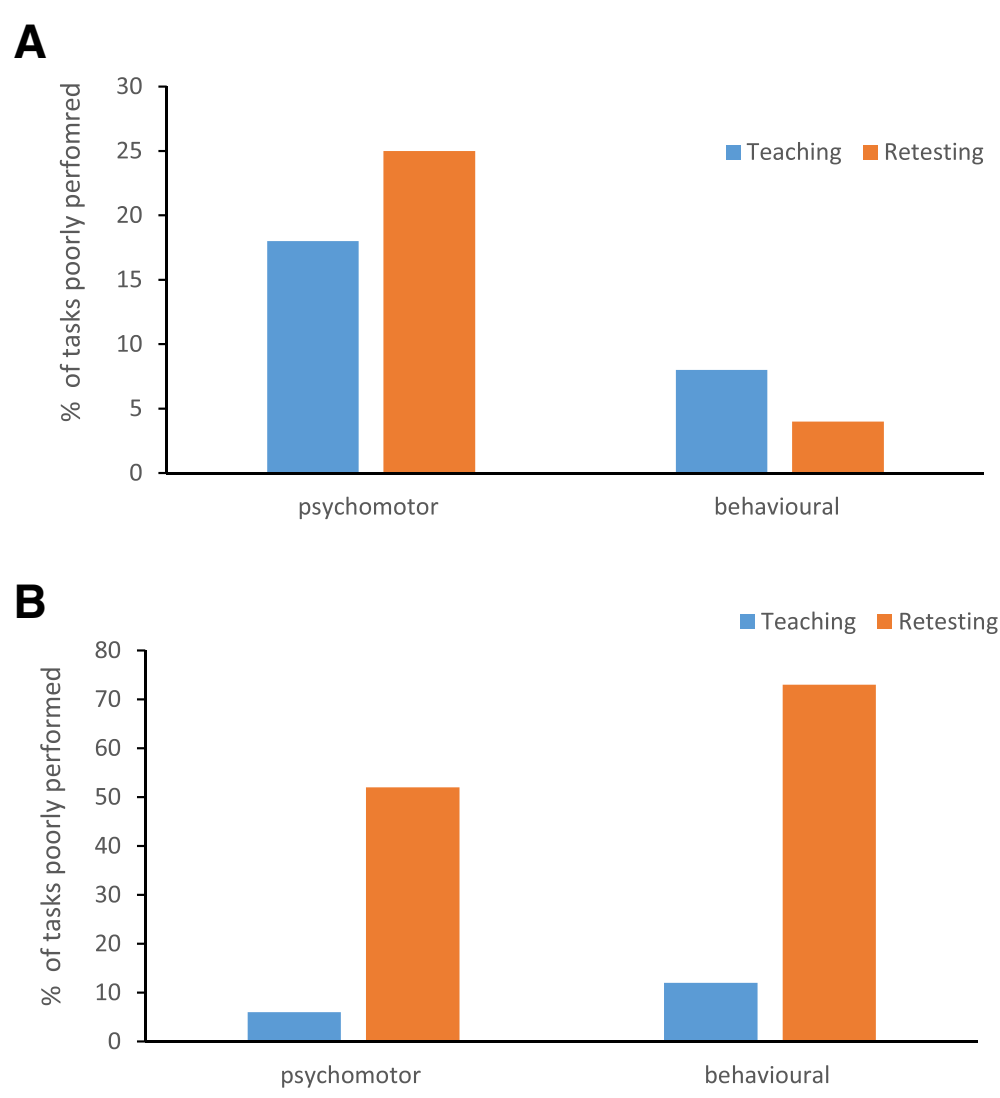

Fig. 1 Percentage of poorly performed tasks. The individual tasks required to perform skills completely were identified under Blooms Taxonomy as psychomotor, behaviour, or knowledge. At the retest of venepuncture, students performed less poorly the behavioural aspects of this task as compared to the psychomotor elements (a). For catheterisation student performed equally poorly on both the psychomotor and behavioural aspects of the tasks (b) 


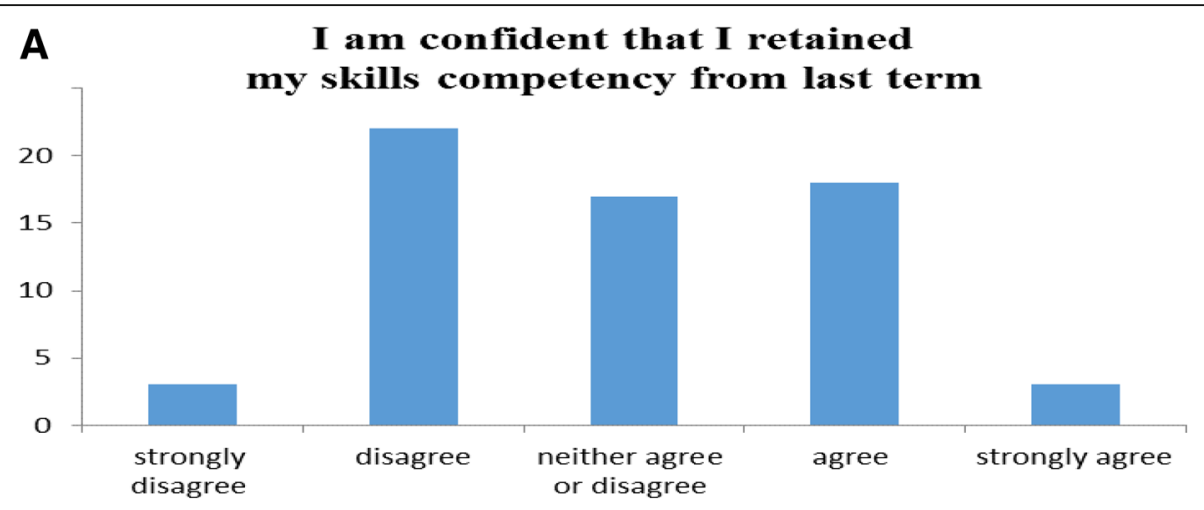

B

I am more confident attending my Sub-I having completed the skills reassessment course.

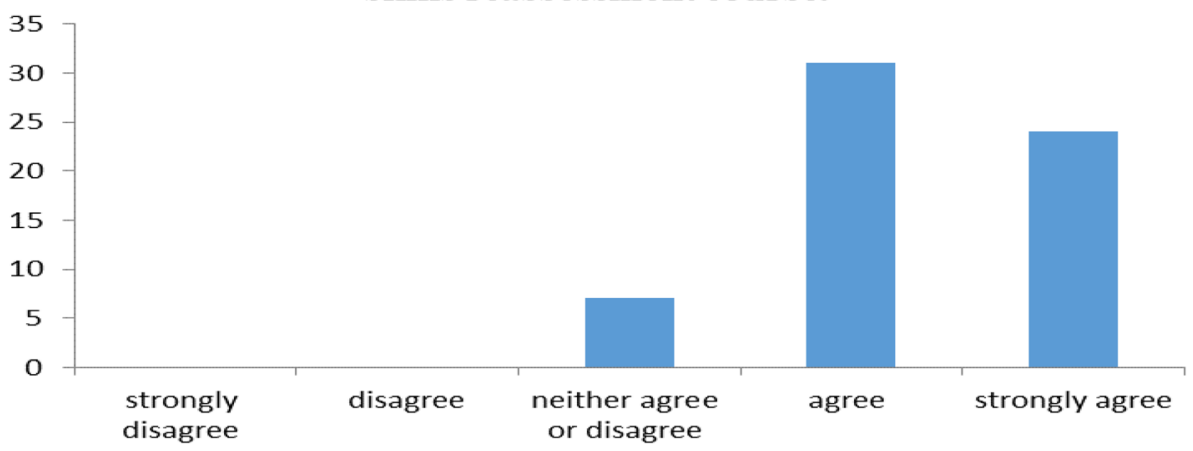

Fig. 2 Students' confidence in own clinical skills pre and post retesting and retraining. Students filled in a questionnaire pre and post-retesting to detail how confident they were at the individual skills. Students were not confident with their own skill levels prior to retesting (a) and they expressed that they were much happier to attend clinical duties post retesting (b). ( $n=51$ students)

complexity reinforcing previous learning will motivate student to do the required repeat practice. A companion e-portfolio log book of practice, reflection and feedback should result in better retention of key skills.

Our study shows that certain dimensions of skills performance are more subject to decay with the passage of time than others. To ensure rigour and relevance an evidenced based approach to curriculum reform is essential. Simulation allows the standardised assessment of learner performance and thus facilitates specific evaluation of a curriculum by collecting evidence to determine if acceptable standards have been met [14]. Simulation can be used to reverse engineer student performance, evaluate performance gaps, and identify knowledge errors and skills deficiencies. Appropriate evaluation of simulation outcomes can close the loop for curriculum development and can facilitate continuous improvement in the educational experience and contribute to curriculum development [15]. Once identified as not competent a work through with a facilitator providing instant feedback was sufficient to restore decayed performance to proficiency on a simulated model which reflects the findings of others $[16,17]$.

Table 4 Medical interns and Medical Educators rate essential skills required for internship

\begin{tabular}{|c|c|c|c|c|c|c|c|c|c|c|}
\hline \multirow{2}{*}{$\begin{array}{l}\text { Required competency } \\
\text { for Intern Practice }\end{array}$} & Intern & Educator & Intern & Educator & Intern & Educator & Intern & Educator & Intern & Educator \\
\hline & \multicolumn{2}{|c|}{ Strongly agree } & \multicolumn{2}{|l|}{ Agree } & \multicolumn{2}{|c|}{ Undecided } & \multicolumn{2}{|c|}{ Disagree } & \multicolumn{2}{|c|}{ Strongly disagree } \\
\hline Venepuncture & $90 \%$ & $83 \%$ & $10 \%$ & $15 \%$ & $0 \%$ & $2 \%$ & $0 \%$ & $0 \%$ & $0 \%$ & $0 \%$ \\
\hline Blood Pressure & $68 \%$ & $95 \%$ & $19 \%$ & $3 \%$ & $10 \%$ & $2 \%$ & $3 \%$ & $0 \%$ & $0 \%$ & $0 \%$ \\
\hline Arterial blood gas & $97 \%$ & $67 \%$ & $6 \%$ & $27 \%$ & $0 \%$ & $5 \%$ & $0 \%$ & $2 \%$ & $0 \%$ & $0 \%$ \\
\hline Urinary catheterisation & $94 \%$ & $68 \%$ & $10 \%$ & $27 \%$ & $0 \%$ & $5 \%$ & $0 \%$ & $0 \%$ & $0 \%$ & $0 \%$ \\
\hline IV Cannulation & $94 \%$ & $80 \%$ & $10 \%$ & $17 \%$ & $0 \%$ & $3 \%$ & $0 \%$ & $0 \%$ & $0 \%$ & $0 \%$ \\
\hline
\end{tabular}

Interns $n=31$, Educators $n=60$

Educators and interns were asked to rate their perceived level of importance of each clinical skill from a list to the clinical practice of a competent intern 


\section{Conclusions and recommendations}

There is significant variation among students with respect to skill decay and this relates directly to practice. Thus, continuous practice needs to be encouraged by tailored experiences and assessments in the clinical setting with emphasis on direct observation and focused feedback to reinforce the skills acquired in the simulated setting. The question remains if performance in simulation can determine undergraduate readiness for performing such procedures on actual patients? How skills practiced and assessed in simulation can be transformed safely into clinical practice needs to be defined by an EPA framework to ensure faculty make competencybased decisions on the level of supervision required by students. To ensure rigour and relevance an evidenced based approach to curriculum reform is essential. Simulation allows the standardized assessment of learner performance and thus facilitates specific evaluation of a curriculum by collecting evidence to determine if acceptable standards have been met. The student body becomes an element in the curriculum reform process as participation provides understanding of the learning that drives the performance.

\section{Abbreviations}

MPS: Minimal Passing Standard; RCSI: Royal College of Surgeons in Ireland; SBE: Simulation Based Education

\section{Acknowledgements}

The authors acknowledge the continued support of the technical staff at the RCSI Simulation Centre and in particular acknowledge the help of Ms. Clare Sullivan who organises the simulated patient bank.

\section{Authors' contributions \\ All persons who meet authorship criteria are listed as authors, and all authors certify that they have participated sufficiently in the work to take public responsibility for the content, including participation in the concept, design, analysis, writing, or revision of the manuscript. All authors approved the submitted version have and agreed both to be personally accountable for the author's own contributions and to ensure that questions related to the accuracy or integrity of any part of the work, even ones in which the author was not personally involved, are appropriately investigated, resolved and the resolution documented in the literature.}

\section{Authors' information}

Ms. Gozie Offiah, MB MRCSI. Senior Lecturer Surgery. Simulation teaching and assessment, Study design, Manuscript editing.

Dr. Lenin. P. Ekpotu M.D. Surgical Tutor, Data collation and analysis, Ms. Siobhan Murphy BSc MSc, Nurse Tutor, Simulation teaching, and assessment.

Dr. Daniel Kane MB, Surgical Tutor, Recruitment Simulation teaching and Assessment.

Dr. Alison Gordon, Surgical Tutor, Simulation teaching, and assessment. Dr. Muireann O'Sullivan, Surgical Tutor, Simulation teaching, and assessment. Dr. Sue Faye Sharifuddin, Medical Tutor, Simulation teaching, and assessment.

Prof ADK Hill. M. D FRCSI Professor of Surgery, Study design, Manuscript editing.

Dr. C.M. Condron MBA Ph.D. Senior Lecturer Simulation, Study design, Ethics application Simulation teaching and assessment, Manuscript writing and editing.

\section{Funding}

This work was funded by The Royal College of Surgeons in Ireland.

\section{Availability of data and materials}

All data analysed during this study are included in this published article. The datasets used and/or analysed during the current study are available from the corresponding author on reasonable request.

\section{Ethics approval and consent to participate}

This work received ethical approval from the Royal College of Surgeons in Ireland's Ethics Committee (\#REC 1362). Informed consent to participate in the study was obtained from each participant.

\section{Consent for publication}

$\mathrm{N} / \mathrm{A}$

\section{Competing interests}

The authors whose names are listed declare that they have no affiliations with or involvement in any organization or entity with any financial interest in this work and have no conflict of interest.

Received: 22 January 2019 Accepted: 11 June 2019

Published online: 16 July 2019

\section{References}

1. Birdane A, Yazici HU, Aydar Y, Mert KU, Masifov M, Ulus T, et al. Effectiveness of cardiac simulator on the acquirement of cardiac auscultatory skills of medical students. Adv Clin Exp Med. 2012;21(6):791-8.

2. Anderson RC, Fagan MJ, Sebastian J. Teaching students the art and science of physical diagnosis. Am J Med. 2001;110(5):419-23.

3. Davis B, Summers M. Applying Dale's cone of experience to increase learning and retention: a study of student learning in a foundational leadership course. Q Science Proceedings. 2015 Jun 1;2015(4):6.

4. Cornock M. Clinical competency in children's nursing: a legal commentary. Nurs Child Young People. 2011;23(10):18-9.

5. Palter VN, Grantcharov T, Harvey A, Macrae HM. Ex vivo technical skills training transfers to the operating room and enhances cognitive learning: a randomized controlled trial. Ann Surg. 2011;253(5):886-9.

6. Kohls-Gatzoulis JA, Regehr G, Hutchison C. Teaching cognitive skills improves learning in surgical skills courses: a blinded, prospective, randomized study. Can J Surg. 2004;47(4):277-83.

7. Singer RN, Chen D. A classification scheme for cognitive strategies: implications for learning and teaching psychomotor skills. Res Q Exerc Sport. 1994;65(2):143-51.

8. Govender K, Rangiah C, Ross A, Campbell L. Retention of knowledge of and skills in cardiopulmonary resuscitation among healthcare providers after training. S Afr Fam Pract. 2010;52(5):459-62.

9. de Ruijter PA, Biersteker HA, Biert J, van Goor H, Tan EC. Retention of first aid and basic life support skills in undergraduate medical students. Med Educ Online. 2014;19:24841.

10. Mwale OG, Kalawa R. Factors affecting acquisition of psychomotor clinical skills by student nurses and midwives in CHAM nursing colleges in Malawi: a qualitative exploratory study. BMC Nurs. 2016;15:30.

11. Stephenson E, Salih Z, Cullen DL. Advanced practice nursing simulation for neonatal skill competency: a pilot study for successful continuing education. J Contin Educ Nurs. 2015:46(7):322-5.

12. Ericsson KA. Deliberate practice and the acquisition and maintenance of expert performance in medicine and related domains. Acad Med. 2004; 79(10 Suppl):S70-81

13. ten Cate $\mathrm{O}$, Chen $\mathrm{HC}$, Hoff RG, Peters $\mathrm{H}$, Bok $\mathrm{H}$, van der Schaaf M. Curriculum development for the workplace using Entrustable professional activities (EPAs): AMEE guide no. 99. Medical Teacher. 2015;37(11):983-1002. https://doi.org/10.3109/0142159X.2015.1060308.

14. Reed T, Pirotte M, McHugh M, Oh L, Lovett S, Hoyt AE, et al. Simulationbased mastery learning improves medical student performance and retention of Core clinical skills. Simul Healthc. 2016:11(3):173-80.

15. Liddell MJ, Davidson SK, Taub H, Whitecross LE. Evaluation of procedural skills training in an undergraduate curriculum. Med Educ. 2002;36(11):1035-41.

16. Kruidering-Hall M, O'Sullivan PS, Chou CL. Teaching feedback to first-year medical students: long-term skill retention and accuracy of student selfassessment. J Gen Intern Med. 2009;24(6):721-6.

17. Vaughn CJ, Kim E, O'Sullivan P, Huang E, Lin MYC, Wyles S, et al. Peer video review and feedback improve performance in basic surgical skills. Am J Surg. 2016;211(2):355-60 


\section{Publisher's Note}

Springer Nature remains neutral with regard to jurisdictional claims in published maps and institutional affiliations.

- fast, convenient online submission

- thorough peer review by experienced researchers in your field

- rapid publication on acceptance

- support for research data, including large and complex data types

- gold Open Access which fosters wider collaboration and increased citations

- maximum visibility for your research: over $100 \mathrm{M}$ website views per year

At $\mathrm{BMC}$, research is always in progress. 